\title{
THE LABOR SUPPLY RESPONSE TO (MISMEASURED BUT) PREDICTABLE WAGE CHANGES
}

\author{
Eric French*
}

\begin{abstract}
Most panel data studies of intertemporal labor supply assume classical measurement error. Recent validation studies refute this assumption. In this study I address nonclassical measurement error explicitly. I use data on males from the Panel Study of Income Dynamics Validation Study to purge measurement error from the Panel Study of Income Dynamics. I find a large amount of predictable wage variation in the data, even after allowing for measurement error. However, there is almost no labor supply response to these predictable wage changes. Therefore, failure to control for nonclassical measurement error cannot explain the low estimated labor supply elasticities in other papers.
\end{abstract}

\section{Introduction}

$\mathrm{T}$ his paper estimates the intertemporal elasticity of substitution, allowing explicitly for measurement error. Several influential studies, using person-specific year-toyear variation in hours and wages, estimate a small (usually between 0 and 0.5$)^{1}$ intertemporal elasticity of substitution (MaCurdy, 1981; Altonji, 1986; Abowd \& Card, 1989; Holtz-Eakin, Newey, \& Rosen, 1988; Ziliak \& Kniesner, 1999; Ham \& Reilly, 2002). All of the studies use data from the Panel Study of Income Dynamics (PSID). However, Heckman (1993) argues that "the low estimated value of the intertemporal-substitution elasticity found in panel data studies appears to be a consequence of non-standard measurement-error problems." ${ }^{2}$

Previous PSID studies assume the measurement error structure their estimation strategy can accommodate, without asking what error structure they should want to accommodate. They assume either that measurement error in hours and wages is white noise (Holtz-Eakin et al., 1988; Ziliak \& Kniesner, 1999) or that it is white noise with a fixed effect (Altonji, 1986; Abowd \& Card, 1987, 1989). These assumptions imply that wages or wage changes 2 years in the past are valid instruments for current wage changes. However, the literature on measurement error indicates that measurement error in hours and wages is not white noise [see the references in Bound, Brown, and Mathiowetz (2001)]. Instead, measurement error in wages is autocorrelated and is

Received for publication August 15, 2000. Revision accepted for publication February 10, 2003.

* Federal Reserve Bank of Chicago.

I thank John Kennan, Rody Manuelli, Jonathan Parker, and Jim Walker for detailed comments and encouragement. I also thank Joe Altonji, Peter Arcidiacono, Meredith Crowley, Nelson Graff, Dan Sullivan, Jim Ziliak, the referees, and seminar participants at the Chicago Fed, SUNY-Stony Brook, and the Econometric Society. Greg Duncan answered many data questions. Financial support provided by the National Institute on Mental Health. The views of the author do not necessarily reflect those of the Federal Reserve System.

${ }^{1}$ These estimates are significantly below the assumed elasticities in most real-business-cycle models. Therefore, the PSID studies cast doubt on the microfoundations of the real-business-cycle literature.

${ }^{2}$ Another potential statistical problem with the PSID studies is smallsample bias. Lee (2001) finds that the estimated intertemporal elasticity of substitution is 0.5 when using standard instruments in the PSID and allowing for small-sample bias. correlated with true hours and wages. This means that using twice lagged wages and wage changes will not overcome the division-bias problem which biases labor supply elasticities downward. ${ }^{3}$

In this study I develop a modified instrumental variables estimator to estimate the intertemporal elasticity of substitution. The estimator allows for the measurement error problems described above. The analysis proceeds as follows.

First, I set up the standard intertemporal labor supply model. The object of interest in this model is the labor supply response to anticipated wage changes. I use last year's wage change to predict this year's wage change. Last year's wage change should have good predictive power if there is a transitory component to wages. A transitory wage change represents an event such as high wages being paid for a short period of time, as in the Alaskan oil pipeline boom of the 1970s (Carrington, 1996). If workers anticipate that transitory wage changes will disappear, then transitory wage changes can identify the labor supply response to anticipated wage changes.

Although using last year's wage change has great power in predicting the current wage change, it introduces potential measurement-error biases. The estimator developed in this paper allows for the covariance of measurement error with true variables and the autocovariances of measurement error.

Finally, I estimate the labor supply response to predictable wage changes, controlling explicitly for measurement error in hours and wages. I estimate the properties of measurement error using the Panel Study of Income Dynamics Validation Study (PSIDVS). I then use this information about measurement error to purge measurement error from the PSID. I find a large transitory component of wages, even after controlling for measurement error.

I find that failure to properly control for measurement error when estimating the intertemporal elasticity of substitution can lead to misleading inferences about the intertemporal elasticity of substitution. However, I also find that controlling explicitly for measurement error does not overturn the conclusions of previous PSID studies of the intertemporal elasticity of substitution. The estimated

\footnotetext{
${ }^{3}$ These problems in the PSID studies motivate several new labor supply studies using natural experiments (Oettinger, 1999; Mulligan, 1995, 1999); Camerer et al., 1997; Carrington, 1996). Although these new studies raise important criticisms, they produce no new consensus. For example, Camerer et al. (1997) estimate the intertemporal elasticity of substitution to be -0.7 , whereas Mulligan's estimate is 2 . One problem with these studies is that they focus on small groups (Camerer et al. on taxicab drivers, Oettinger on stadium vendors) or isolated instances (Carrington measures the intertemporal elasticity of substitution using evidence from the Alaska oil pipeline boom). These specific cases may not generalize to the population as a whole.
} 
intertemporal elasticity of substitution is close to 0 with a standard error of 0.25 .

The paper proceeds as follows. Section II describes the labor supply model and how I control for measurement error when estimating the intertemporal elasticity of substitution. Section III describes the PSID data. It also describes the PSIDVS data that I use to estimate the properties of measurement error. Section IV presents estimates of the model of wage dynamics and estimates of the intertemporal elasticity of substitution. Section V concludes.

\section{Estimating the Intertemporal Elasticity of Substitution}

In this section I present a standard life cycle labor supply model. I also present a wage prediction equation. The central implication of the life cycle labor supply model is that hours changes are positively correlated with predictable wage changes. Lastly, I consider how to address issues of measurement error in estimating the labor supply response to predictable wage changes.

\section{B. The Intertemporal Labor Supply Model}

I begin with the standard intertemporal labor supply model. The specification is similar to that of MaCurdy (1985). Preferences take the form

$$
U=E_{0} \sum_{t=1}^{T} \beta^{t}\left(v\left(c_{i t}\right)-\exp \left(-\alpha_{i t} / \sigma\right) \times \frac{h_{i t}^{1+1 / \sigma}}{1+1 / \sigma}\right),
$$

where $U$ is the expected discounted present value of lifetime utility, $c_{i t}$ is consumption, $v(\cdot)$ is some increasing concave function, and $h_{i t}$ is hours worked. The parameter $\sigma$ is the intertemporal elasticity of substitution, which is the object of interest in this study. Lastly, $\alpha_{i t}$ is the preference for work. Define $A_{i t}$ as assets, $r_{t}$ the interest rate, and $W_{i t}$ the true wage. Individuals choose labor supply ${ }^{4}$ and consumption paths to maximize equation (1) subject to the dynamic budget constraint

$$
A_{i t+1}=\left(1+r_{t}\right)\left(A_{i t}+W_{i t} h_{i t}-c_{i t}\right),
$$

which results in the labor supply function

$$
\log h_{i t}=\sigma \log W_{i t}+\sigma \log \lambda_{i t}+\alpha_{i t}
$$

which in first differences is

$$
\Delta \log h_{i t}=\sigma \Delta \log W_{i t}+\sigma \Delta \log \lambda_{i t}+\Delta \alpha_{i t}
$$

\footnotetext{
${ }^{4}$ Most labor supply models assume that individuals choose their work hours given the wage. This rules out the complications created by contracting models [see Rosen (1985) and Abowd and Card (1987), for example].
}

where $\Delta$ is the first difference operator (for example, $\Delta \log$ $\left.h_{i t}=\log h_{i t}-\log h_{i t-1}\right)$ and $\lambda_{i t}$ is the marginal utility of wealth.

The Euler equation implies that individuals equate expected marginal utility across time according to

$$
\lambda_{i t-1}=\beta\left(1+r_{t-1}\right) E_{t-1} \lambda_{i t},
$$

where rational expectations 5 implies that innovations to the marginal utility of wealth, denoted $\varepsilon_{i t}$, should be uncorrelated with lagged values of the marginal utility of wealth:

$$
\lambda_{i t}=E_{t-1} \lambda_{i t}+\varepsilon_{i t} .
$$

Equations (5) and (6) can be rewritten as

$$
\frac{\beta\left(1+r_{t-1}\right) \lambda_{i t}}{\lambda_{i t-1}}=1+\frac{\beta\left(1+r_{t-1}\right) \varepsilon_{i t}}{\lambda_{i t-1}} .
$$

Taking logarithms of both sides of equation (7) and approximating $\log \left[1+\left(\beta\left(1+r_{t-1}\right) \varepsilon_{i t} / \lambda_{i t-1}\right)\right]$ yields

$$
\begin{aligned}
& \log \lambda_{i t}-\log \lambda_{i t-1}+\log \beta\left(1+r_{t-1}\right) \\
& =\log \left(1+\frac{\beta\left(1+r_{t-1}\right) \varepsilon_{i t}}{\lambda_{i t-1}}\right) \approx \frac{\beta\left(1+r_{t-1}\right) \varepsilon_{i t}}{\lambda_{i t-1}} .
\end{aligned}
$$

Throughout I will assume that the approximation in equation (8) holds with equality. As innovations in the marginal utility of wealth become arbitrarily small, equation (8) becomes an arbitrarily close approximation.

Combining equations (8) and (4) results in

$$
\begin{gathered}
\Delta \log h_{i t}=\sigma \Delta \log W_{i t}-\sigma \log \beta\left(1+r_{t-1}\right) \\
+\sigma \frac{\beta\left(1+r_{t-1}\right) \varepsilon_{i t}}{\lambda_{i t-1}}+\Delta \alpha_{i t} .
\end{gathered}
$$

The object of interest in this study is $\sigma$, which is a measure of the substitution effect associated with a wage change.

\section{B. Using Lagged Wage Changes to Predict Current Wage Changes}

Equation (9) shows that there are three determinants of hours changes that are potentially correlated with wage changes: the interest rate, preference changes, and expectation errors. I must control for all three objects in order to obtain a consistent estimate of $\sigma$. In the analysis, I remove the correlation between wage changes and both the interest rate and preference changes by using residuals from regressions of wage and hours changes on a full set of year dummy variables, health status, age, and education. ${ }^{6}$

\footnotetext{
${ }^{5}$ If workers have rational expectations, then at time $t$ they know their state variables $\Delta \log W_{i t}, r_{t}, \alpha_{i t}$, and the Markov process that determines the evolution of the state variables, and they optimize accordingly.

${ }^{6}$ Section III describes the procedure more fully. By construction, the hours residuals are uncorrelated with the year effects (and thus the interest rate) and with observable preference shifters such as health. Using these
} 
Throughout the rest of the paper, $\log W_{i t}$ is redefined as the true wage residual and $\log h_{i t}$ is redefined as the true hours residual. $^{7}$

Time $t$ wage changes $\Delta \log W_{i t}$ are correlated with the time $t$ expectation errors $\varepsilon_{i t}$ if wage changes are unanticipated. However, if individuals have rational expectations, then expectation errors are uncorrelated with information known to the individual at time $t-1$. Therefore, the wage can be instrumented using time $t-1$ information. A natural instrument is last year's wage change, $\Delta \log W_{i t-1}$. Consider the following model of wage growth:

$$
\Delta \log W_{i t}=\delta+\gamma \Delta \log W_{i t-1}+\eta_{i t} .
$$

The predicted wage growth $\Delta \widehat{\log W}_{\mathrm{it}}$ is then

$$
\Delta \widehat{\log }_{\mathrm{it}}=\delta+\gamma \Delta \log W_{i t-1} .
$$

Individuals may use more information than what is used in equation (11), but must use at least the information used in equation (11) when forecasting wage changes.

Inserting equation (11) into equation (9) (and netting out year effects and preference shifters) shows that the instrumental variables estimate of $\sigma$ is

$$
\begin{aligned}
\sigma & =\frac{\operatorname{Cov}\left(\Delta \log h_{i t}, \Delta \widehat{\log }_{\mathrm{it}}\right)}{\operatorname{Cov}\left(\Delta \log W_{i t}, \Delta \widehat{\log }_{\mathrm{it}}\right)} \\
& =\frac{\operatorname{Cov}\left(\Delta \log h_{i t}, \Delta \log W_{i t-1}\right)}{\operatorname{Cov}\left(\Delta \log W_{i t}, \Delta \log W_{i t-1}\right)},
\end{aligned}
$$

where the above objects are population moments. The labor supply response to these predictable wage changes identifies the intertemporal elasticity of substitution. For example, if wages have a transitory component, wage changes will be negatively correlated across time, that is, $\operatorname{Cov}\left(\Delta \log W_{i t}, \Delta\right.$ $\left.\log W_{i t-1}\right)<0$. Testing whether $\sigma$ is positive will then be equivalent to testing whether $\operatorname{Cov}\left(\Delta \log h_{i t}, \Delta \log W_{i t-1}\right)$ is negative.

\section{The Problem of Measurement Error}

Given that measurement error is pervasive in wage and hours data, it must be purged from equation (12). In most studies, measurement error is assumed to be white noise (Altonji, 1986; Holtz-Eakin et al., 1988; Ziliak \& Kniesner, 1999) or white noise with a fixed effect (Abowd \& Card, 1987, 1989). However, validation studies (Bound et al., 2001) have refuted these assumptions. The validation studies have shown that measurement error in wages and hours is negatively correlated with true wages and hours. Bound et al. (1994) refer to this as mean-reverting measurement error.

hours residuals, the only determinants of hours changes will be wage changes and unobserved preference changes.

7 The relationship between measured hours, the measured hours residual, and the true hours residual is described in equations (14) and (25).
One potential explanation for mean-reverting measurement error is that workers under-report transitory changes in wages and hours. ${ }^{8}$

The validation studies also suggest that the serial correlation properties of measurement error may be more complicated than a simple fixed effect. Whereas Bound et al. (1994) find only a 0.09 correlation in measurement error in earnings 4 years apart in the PSIDVS, Bound and Krueger (1991) find a 0.38 correlation in measurement error in earnings 2 years apart when comparing matched CPS data with social security earnings records. Note that if the measurement error in earnings were white noise with a fixed effect, the correlation of measurement error 2 years apart should be the same as the correlation of measurement error 4 years apart. ${ }^{9}$

Many models of measurement error are consistent with the evidence; a MA(1) process with a fixed effect is a parsimonious model that is consistent with the evidence.

Therefore, consider the following model of measured hours and wages: ${ }^{10}$

$$
\begin{aligned}
& \log \tilde{W}_{i t}=\log W_{i t}+u_{w i t}, \\
& \log \tilde{h}_{i t}=\log h_{i t}+u_{h i t} .
\end{aligned}
$$

The measurement errors in wages and hours follow

$$
\begin{aligned}
& u_{w i t}=u_{w i}+v_{w i t}+\theta_{w} v_{w i t-1}, \\
& u_{h i t}=u_{h i}+v_{h i t}+\theta_{h} v_{h i t-1},
\end{aligned}
$$

where innovations to the transitory component of measurement error are correlated with the transitory component of wages but not with any autocorrelated component of wages, that is, $\operatorname{Cov}\left(v_{\text {wit }}, \log W_{i t}\right) \neq 0, \operatorname{Cov}\left(v_{\text {wit }}, v_{\text {hit }}\right) \neq 0$, but $\operatorname{Cov}\left(v_{w i t}, \log W_{i t-k}\right)=0, \operatorname{Cov}\left(v_{w i t}, v_{w i t-k}\right)=0$ for all $k \neq 0$. Moreover, assume that all the covariances of measurement error are stationary, that is, $\operatorname{Cov}\left(\log W_{i t-1}\right.$, $\left.v_{w i t-1}\right)=\operatorname{Cov}\left(\log W_{i t}, v_{w i t}\right)$ and $\operatorname{Cov}\left(v_{w i t-1}, v_{h i t-1}\right)=$ $\operatorname{Cov}\left(v_{w i t}, v_{h i t}\right)$. In appendix B I show that first-differencing equations (13)-(16) and then inserting these equations into equation (12) results in a specification for $\sigma=(\operatorname{Cov}(\Delta \log$ $\left.\left.h_{i t}, \Delta \log W_{i t-1}\right)\right) /\left(\operatorname{Cov}\left(\Delta \log W_{i t}, \Delta \log W_{i t-1}\right)\right)$, where

\footnotetext{
${ }^{8}$ This may be evidence that workers tend to forget short-term changes in hours and wages. If so, it seems unlikely that workers think seriously about adjusting their work hours to transitory wage fluctuations.

${ }^{9}$ Bound et al.'s (1994) study and Bound and Krueger's (1991) study use different data sets, and each has its own idiosyncratic problems. For example, one problem with the CPS study is that that some people interviewed during this time period potentially had more than one social security number. Therefore, the validation procedure is flawed when using social security records as a validation source. The correlation of measurement error could be the result of two successive mismatches between the CPS and the social security records. Moreover, the PSID is a higherquality data set. Problems of autocorrelation of measurement error that exist in the CPS may not exist in the PSID. The data section describes some of the problems with the PSIDVS. Nevertheless, the two studies give evidence that measurement error may be more complicated than white noise with a fixed effect.

${ }^{10}$ Recall these are measured hours and wage residuals.
} 


$$
\begin{aligned}
& \operatorname{Cov}\left(\Delta \log h_{i t}, \Delta \log W_{i t-1}\right) \\
& =\operatorname{Cov}\left(\Delta \log \tilde{h}_{i t}, \Delta \log \tilde{W}_{i t-1}\right)+\left(1-2 \theta_{h}\right. \\
& \left.\quad+\theta_{h} \theta_{w}\right) \operatorname{Cov}\left(v_{h i t}, v_{w i t}\right)+\operatorname{Cov}\left(v_{w i t}, \log h_{i t}\right) \\
& \quad+\left(1-2 \theta_{h}\right) \operatorname{Cov}\left(v_{h i t}, \log W_{i t}\right)
\end{aligned}
$$

and

$$
\begin{aligned}
& \operatorname{Cov}\left(\Delta \log W_{i t}, \Delta \log W_{i t-1}\right) \\
& =\operatorname{Cov}\left(\Delta \log \tilde{W}_{i t}, \Delta \log \tilde{W}_{i t-1}\right) \\
& \quad+\left(2-2 \theta_{w}\right) \operatorname{Cov}\left(\log W_{i t}, v_{w i t}\right) \\
& \quad+\left(1-2 \theta_{w}+\theta_{w}^{2}\right) \operatorname{Var}\left(v_{w i t}\right)
\end{aligned}
$$

Wages are usually imputed using earnings divided by hours. ${ }^{11}$ Therefore, an over-report of hours leads to an underreport of wages, making measurement error in hours negatively correlated with measurement error in wages, that is, $\operatorname{Cov}\left(v_{h i t}, v_{w i t}\right)<0$. Failure to include this term will bias the estimate of $\operatorname{Cov}\left(\Delta \log h_{i t}, \Delta \log W_{i t-1}\right)$ upward. ${ }^{12}$

Note that $\operatorname{Var}\left(v_{w i t}\right)$ is positive. Thus, failure to control for this term will bias the estimate of $\operatorname{Cov}\left(\Delta \log W_{i t}, \Delta \log \right.$ $\left.W_{i t-1}\right)$ downward. Given that failure to control for measurement error biases $\operatorname{Cov}\left(\Delta \log h_{i t}, \Delta \log W_{i t-1}\right)$ upward and $\operatorname{Cov}\left(\Delta \log W_{i t}, \Delta \log W_{i t-1}\right)$ downward, the intertemporal elasticity of substitution will most likely be biased downward. This problem, known as division bias, is well recognized in the labor supply literature.

What is less well recognized, however, is how meanreverting measurement error should affect the estimate of the intertemporal elasticity of substitution. Equations (17) and (18) show that the covariance between measurement error and true hours and wages can also create bias.

\section{Sources of Bias When Twice Lagged Wage Changes Instrument for Current Wage Changes}

As stated previously, many researchers use twice lagged wages or twice lagged wage changes to instrument for current wage changes. After controlling for preference shifters and the interest rate, the intertemporal elasticity of substitution when using twice lagged wage changes [used by Abowd and Card (1987, 1989), for example] as an instrument is

\footnotetext{
${ }^{11}$ Some authors use alternative wage measures (Altonji, 1986; Ziliak \& Kniesner, 1999) which potentially overcome the problems mentioned herein. However, Altonji (1986) measures the intertemporal elasticity for a subset of the population. Moreover, his measure of the wage does not include bonuses and overtime, a potentially important source of variability in wages. Ziliak and Kniesner (1999) use earnings divided by a constant. If hours are autocorrelated but have a correlation coefficient less than 1 , their procedure will produce upward-biased estimates of the intertemporal elasticity of substitution.

${ }^{12}$ This is true only when $\left(1-2 \theta_{h}+\theta_{h} \theta_{w}\right)>0$, or when $\theta_{h}$ and $\theta_{w}$ are not too big. Unfortunately, we have little evidence on these two parameters. Assuming that the measurement error properties of earnings in the CPS are the same as those for hours and wages in the PSID, results from Bound and Krueger (1991) indicate that this inequality holds.
}

$$
\begin{gathered}
\sigma=\frac{\operatorname{Cov}\left(\Delta \log h_{i t}, \Delta \log W_{i t-2}\right)}{\operatorname{Cov}\left(\Delta \log W_{i t}, \Delta \log W_{i t-2}\right)} \\
\begin{array}{c}
\operatorname{Cov}\left(\Delta \log \tilde{h}_{i t}, \Delta \log \tilde{W}_{i t-2}\right) \\
+\theta_{h}\left[\operatorname{Cov}\left(v_{h i t}, \log W_{i t}\right)+\operatorname{Cov}\left(v_{h i t}, v_{w i t}\right)\right. \\
\quad \operatorname{Cov}\left(\Delta \log \tilde{W}_{i t}, \Delta \log \tilde{W}_{i t-2}\right) \\
\quad+\theta w\left[\operatorname{Cov}\left(v_{w i t}, \log W_{i t}\right)+\operatorname{Var}\left(v_{w i t}\right)\right.
\end{array}
\end{gathered}
$$

When using twice lagged wage levels as an instrument for the wage change [used by Holtz-Eakin et al. (1988) and Ziliak and Kniesner (1999)], the intertemporal elasticity of substitution is

$$
\begin{gathered}
\sigma=\frac{\operatorname{Cov}\left(\Delta \log h_{i t}, \Delta \log W_{i t-2}\right)}{\operatorname{Cov}\left(\Delta \log W_{i t}, \log W_{i t-2}\right)} \\
=\frac{\operatorname{Cov}\left(\Delta \log \tilde{h}_{i t}, \log \tilde{W}_{i t-2}\right)-\operatorname{Cov}\left(\Delta \log h_{i t}, u_{w i}\right)}{+\theta_{h}\left[\operatorname{Cov}\left(v_{h i t}, \log W_{i t}\right)+\operatorname{Cov}\left(v_{h i t}, v_{w i t}\right)\right]} \\
\begin{array}{c}
\operatorname{Cov}\left(\Delta \log \tilde{W}_{i t}, \log \tilde{W}_{i t-2}\right)-\operatorname{Cov}\left(\Delta \log W_{i t}, u_{w i}\right) \\
+\theta w\left[\operatorname{Cov}\left(v_{w i t}, \log W_{i t}\right)+\operatorname{Var}\left(v_{w i t}\right)\right]
\end{array}
\end{gathered}
$$

Equations (19) and (20) show that using twice lagged wage levels and changes are only valid instruments if measurement error has no $\mathrm{MA}(1)$ component, that is, $\theta_{h}=\theta_{w}=0$. If $\theta_{h}>0$ and $\operatorname{Cov}\left(v_{h i t}, v_{w i t}\right)<0$, the numerator in equations (19) and (20) is biased upward. Likewise, the denominators in equations (19) and (20) are biased downward. This likely leads to a downward-biased estimate of $\sigma$. In other words, using twice lagged wage changes only overcomes the division bias problem when there is no MA(1) measurement error component.

\section{E. Estimating Equations}

The restrictions necessary to identify the intertemporal elasticity of substitution [the ratio of equation (17) to (18)] are described in table 1 . The first five restrictions in table 1 follow from equations (15) and (16) and the orthogonality and stationarity assumptions described immediately below equation (16). However, given the data in the next section, both $\theta_{w}$ and $\theta_{h}$ are still unknown without making further assumptions. In order to identify the MA(1) measurement error coefficients $\theta_{h}$ and $\theta_{w}$ using data, we need information on the correlation of measurement error across two adjacent years. Unfortunately, this does not exist in the available data. Therefore, I consider two alternative sets of assumptions about the values of $\theta_{w}$ and $\theta_{h}$. Each set of assumptions enables me to identify the intertemporal elasticity of substitution.

Under assumption (A1) I assume $\theta_{w}=0$ and $\theta_{h}=0$. Assumption (A1) and the assumptions in section IIC result in the final two identifying restrictions listed in table 1. 
Table 1.-Properties of Transitory Measurement Error

\begin{tabular}{cc}
\hline \hline Object of Interest & $\begin{array}{c}\text { Data Used to Estimate } \\
\text { Object of Interest }\end{array}$ \\
\hline $\operatorname{Cov}\left(\log h_{i t}, v_{w i t}\right)$ & $\operatorname{Cov}\left(\log h_{i t}, u_{w i t}\right)$ \\
& $-\operatorname{Cov}\left(\log h_{i t}, u_{w i t+k}\right),|k|>1$ \\
$\left(1+\theta_{h} \theta_{w}\right) \operatorname{Cov}\left(v_{h i t}, v_{w i t}\right)$ & $\operatorname{Cov}\left(u_{h i t}, u_{w i t}\right)$ \\
& $-\operatorname{Cov}\left(u_{h i t}, u_{w i t+k}\right),|k|>1$ \\
$\operatorname{Cov}\left(\log W_{i t}, v_{h i t}\right)$ & $\operatorname{Cov}\left(\log W_{i t}, u_{h i t}\right)$ \\
& $-\operatorname{Cov}\left(\log W_{i t}, u_{h i t+k}\right),|k|>1$ \\
$\operatorname{Cov}\left(\log W_{i t}, v_{w i t}\right)$ & $\operatorname{Cov}\left(\log W_{i t}, u_{w i t}\right)$ \\
$\left(1+\theta_{w}^{2}\right) \operatorname{Var}\left(v_{w i t}\right)$ & $-\operatorname{Cov}\left(\log W_{i t}, u_{w i t+k}\right),|k|>1$ \\
$-\theta_{w}\left[\operatorname{Cov}\left(\log W_{i t}, v_{w i t}\right)\right.$ & $\operatorname{Var}\left(u_{w i t}\right)-\operatorname{Cov}\left(u_{w i t}, u_{w i t}\right)$, \\
$\left.+\operatorname{Var}\left(v_{w i t}\right)\right]$ & $|k|>1$ \\
$-\theta_{h}\left[\operatorname{Cov}\left(\log W_{i t}, v_{h i t}\right)\right.$ & $(\mathrm{A} 1) \quad 0$ \\
$\left.+\operatorname{Cov}\left(v_{w i t}, v_{h i t}\right)\right]$ & $(\mathrm{A} 1) \quad 0$ \\
\hline
\end{tabular}

The first five identification restrictions are derived using the assumptions in section IIC (A1) and (A2) are only necessary for identifying the last two objects of interest.

(A1) is the set of assumptions that lead to estimating equations (21) and (22).

(A2) is the set of assumptions that lead to estimating equations (23) and (24).

Using these identifying assumptions, equations (17) and (18) can be rewritten as

$$
\begin{aligned}
\operatorname{Cov} & \left(\Delta \log h_{i t}, \Delta \log W_{i t-1}\right) \\
= & \operatorname{Cov}\left(\Delta \log \tilde{h}_{i t}, \Delta \log \tilde{W}_{i t-1}\right)+\left[\operatorname{Cov}\left(\log h_{i t}, u_{w i t}\right)\right. \\
& \left.-\operatorname{Cov}\left(\log h_{i t}, u_{w i t-k}\right)\right]+\left[\operatorname{Cov}\left(u_{h i t}, \log W_{i t}\right)\right. \\
& \left.-\operatorname{Cov}\left(u_{h i t-k}, \log W_{i t}\right)\right]+\left[\operatorname{Cov}\left(u_{h i t}, u_{w i t}\right)\right. \\
& \left.-\operatorname{Cov}\left(u_{h i t}, u_{w i t-k}\right)\right],
\end{aligned}
$$

$\operatorname{Cov}\left(\Delta \log W_{i t}, \Delta \log W_{i t-1}\right)$

$=\operatorname{Cov}\left(\Delta \log \tilde{W}_{i t}, \Delta \log \tilde{W}_{i t-1}\right)+2\left[\operatorname{Cov}\left(\log W_{i t}, u_{w i t}\right)\right.$

$$
\begin{aligned}
& \left.-\operatorname{Cov}\left(\log W_{i t}, u_{w i t-k}\right)\right]+\left[\operatorname{Var}\left(u_{w i t}\right)\right. \\
& \left.-\operatorname{Cov}\left(u_{w i t}, u_{w i t-k}\right)\right]
\end{aligned}
$$

for $|k|>1$.

In assumption (A2) I assume that

$$
\theta_{w}=-\frac{\operatorname{Cov}\left(\Delta \log \tilde{W}_{i t}, \Delta \log \tilde{W}_{i t-2}\right)}{\operatorname{Cov}\left(\log W_{i t}, v_{w i t}\right)+\operatorname{Var}\left(v_{w i t}\right)}
$$

and

$$
\theta_{h}=-\frac{\operatorname{Cov}\left(\Delta \log \tilde{h}_{i t}, \Delta \log \tilde{W}_{i t-2}\right)}{\operatorname{Cov}\left(\log W_{i t}, v_{h i t}\right)+\operatorname{Cov}\left(v_{w i t}, v_{h i t}\right)}
$$

Assumption (A2) is equivalent to assuming $\operatorname{Cov}\left(\Delta \log W_{i t}\right.$, $\left.\Delta \log W_{i t-2}\right)=0$ and $\operatorname{Cov}\left(\Delta \log h_{i t}, \Delta \log W_{i t-2}\right)=0$, that is, all autocorrelation between measured wage changes and their second lags arises from the autocorrelation of measurement error. Assumption (A2) is satisfied if $\log$ wages are a random walk with white noise superimposed.
Given these assumptions, equations (17) and (18) can be rewritten as

$$
\begin{aligned}
& \operatorname{Cov}\left(\Delta \log h_{i t}, \Delta \log W_{i t-1}\right) \\
& =\operatorname{Cov}\left(\Delta \log \tilde{h}_{i t}, \Delta \log \tilde{W}_{i t-1}\right)+\left[\operatorname{Cov}\left(\log h_{i t}, u_{w i t}\right)\right. \\
& \left.\quad-\operatorname{Cov}\left(\log h_{i t}, u_{w i t-k}\right)\right]+\left[\operatorname{Cov}\left(u_{h i t}, \log W_{i t}\right)\right. \\
& \left.\quad-\operatorname{Cov}\left(u_{h i t-k}, \log W_{i t}\right)\right]+\left[\operatorname{Cov}\left(u_{h i t}, u_{w i t}\right)\right. \\
& \left.\quad-\operatorname{Cov}\left(u_{h i t}, u_{w i t-k}\right)\right]+2 \operatorname{Cov}\left(\Delta \log \tilde{h}_{i t}, \Delta \log \tilde{W}_{i t-2}\right), \\
& \operatorname{Cov}\left(\Delta \log W_{i t}, \Delta \log W_{i t-1}\right) \\
& =\operatorname{Cov}\left(\Delta \log \tilde{W}_{i t}, \Delta \log \tilde{W}_{i t-1}\right)+2\left[\operatorname{Cov}\left(\log W_{i t}, u_{w i t}\right)\right. \\
& \left.\quad-\operatorname{Cov}\left(\log W_{i t}, u_{w i t-k}\right)\right]+\left[\left(\operatorname{Var}\left(u_{w i t}\right)\right.\right. \\
& \left.\quad-\operatorname{Cov}\left(u_{w i t}, u_{w i t-k}\right)\right] \\
& \quad+2 \operatorname{Cov}\left(\Delta \log \tilde{W}_{i t}, \Delta \log \tilde{W}_{i t-2}\right)
\end{aligned}
$$

for $|k|>1$. The two estimates of the intertemporal elasticity of substitution that I present in this paper are the ratio of equation (21) to (22) and the ratio of equation (23) to (24).

\section{Data}

Given the scheme for estimating the intertemporal elasticity of substitution presented above, I need information on the properties of measured wages and hours (namely, the variances and covariances of their residuals) as well as the properties of the measurement error (namely, its variances and covariances). I use the PSID for measuring the properties of measured wages and hours, and the PSIDVS for measuring the properties of the measurement error.

Table 2 describes some basic characteristics of the PSID and PSIDVS samples. Because the PSIDVS sample only has hourly workers, I show results both for all male workers in the PSID and for male hourly workers in the PSID. The PSIDVS sample is older, is less educated, and has higher wages than both the full and hourly PSID samples. Most importantly, there is a "true" wage and hours measure, which will be described below.

TABLE 2.-Descriptive Statistics: PSID (1980-1986) AND PSIDVS $(1982,1986)$

\begin{tabular}{lccc}
\hline \hline \multirow{2}{*}{\multicolumn{1}{c}{ Variable }} & \multicolumn{3}{c}{ Mean (Standard Deviation) } \\
\cline { 2 - 4 } & PSID, all & $\begin{array}{c}\text { PSID, } \\
\text { hourly }\end{array}$ & PSIDVS \\
\hline Age & $38.9(10.6)$ & $37.9(10.9)$ & $45.9(16.0)$ \\
At least high school grad.? & $0.84(0.37)$ & $0.73(0.44)$ & $0.65(0.35)$ \\
College grad.? & $0.30(0.44)$ & $0.07(0.26)$ & $0.12(0.33)$ \\
Tenure & $9.5(8.9)$ & $8.9(8.7)$ & $15.1(11.8)$ \\
Log reported wage & $2.50(0.55)$ & $2.40(0.46)$ & $2.90(0.19)$ \\
Log reported hours & $7.66(0.29)$ & $7.60(0.27)$ & $7.59(0.19)$ \\
Log true wage & & & $2.92(0.11)$ \\
Log true hours & & & $7.57(0.21)$ \\
& $N=14,920$ & $N=5,521$ & $N=544$ \\
\hline
\end{tabular}




\section{A. PSID Data}

The data source used to estimate the properties of measured wages is a male subsample of the PSID for the years 1981-1987, collected by researchers at the University of Michigan. I restrict the PSID sample to the years 1981-1987 to maximize how comparable the PSID is to the PSIDVS, which has data on hours and wages and measurement error in hours and wages for 1982 and 1986. I exclude the Survey of Economic Opportunity (SEO) subsample, which oversamples the poor and minorities. Survey respondents are asked about their earnings, labor supply patterns, and other decisions during the previous calendar year. Therefore, responses are for the years 1980-1986. Wages are imputed using annual earnings divided by annual hours. Appendix A describes the sample selection criteria.

As described in section IIB, I posit the following model of measured $\log$ hours changes $\left(\Delta \log h_{i t}^{*}\right)$ and wage changes $\left(\Delta \log W_{i t}^{*}\right)$ :

$$
\begin{aligned}
& \Delta \log h_{i t}^{*}=X_{i t} G+\Delta \log \tilde{h}_{i t}, \\
& \Delta \log W_{i t}^{*}=X_{i t} B+\Delta \log \tilde{W}_{i t},
\end{aligned}
$$

where $X_{i t}$ is a vector of personal characteristics and year dummy variables, and $\Delta \log \tilde{h}_{i t}$ and $\Delta \log \tilde{W}_{i t}$ are the hours and wage residuals. Included in $X_{i t}$ are year dummies, a third-order age polynomial, education, and health. Note that $\Delta \log \tilde{W}_{i t}$ is orthogonal to the interest rate by construction, as it is orthogonal to the year effects. It is also orthogonal to observable preference shifters such as health. Table 3 presents estimates for hours and wages in 1980-1987. The most striking aspect of the regressions in table 3 is how little of the variation in wages and hours these variables can explain. Note that these variables, except health, are the usual instruments for wages when estimating labor supply functions. The $R^{2}$ is 0.0111 for hours and 0.0055 for wages. In other words, variation in the business cycle, age, education, and health explains only $0.55 \%$ of the variation in wage movements and $1.11 \%$ of the variation in hours movements. The focus of this paper will be on the labor

TABle 3.-OLS Regressions For Wage AND Hours Changes, PSID, 1980-1987

\begin{tabular}{lcc}
\hline \hline & \multicolumn{2}{c}{ Estimate (S.E.) } \\
\cline { 2 - 3 } & $\Delta \log h_{i t}$ & $\Delta \log W_{i t}$ \\
\hline Intercept & $.064(.18)$ & $.018(.22)$ \\
Age & $-.050(.013)$ & $.0028(.0165)$ \\
Age squared & $.0013(.0003)$ & $-.00014(.00039)$ \\
Age cubed & $-.000011(.000002)$ & $.0000014(.0000030)$ \\
College grad. & $.045(.006)$ & $.025(.0007)$ \\
High school & $.040(.007)$ & $-.0005(.0087)$ \\
Health change & $-.017(.009)$ & $-.052(.012)$ \\
$R^{2}$ & 0.0111 & 0.0055 \\
$F$-statistic & 11.1 & 5.31 \\
$N$ & 11,869 & 11,539 \\
\hline Year dummies also included. & &
\end{tabular}

Year dummies also included.
Table 4.-Covariance of Hours and Wage Changes with LAGged Wage Changes, PSID, 1980-1986

All Workers

\begin{tabular}{lr}
$\operatorname{Cov}\left(\Delta \log \tilde{h}_{i t}, \Delta \log \tilde{W}_{i t-1}\right)=$ & $\operatorname{Cov}\left(\Delta \log \tilde{W}_{i t}, \Delta \log \tilde{W}_{i t-1}\right)=$ \\
$.0090(.0015)$ & $-.0366(.0028)$ \\
$\operatorname{Cov}\left(\Delta \log \tilde{h}_{i t}, \Delta \log \tilde{W}_{i t-2}\right)=$ & $\operatorname{Cov}\left(\Delta \log \tilde{W}_{i t}, \Delta \log \tilde{W}_{i t-2}\right)=$ \\
$.0013(.0014)$ & $-.0009(.0014)$ \\
\multicolumn{3}{c}{ Hourly $\begin{array}{l}\text { Workers } \\
\operatorname{Cov}\left(\Delta \log \tilde{h}_{i t}, \Delta \log \tilde{W}_{i t-1}\right)=\end{array}$} & $\operatorname{Cov}\left(\Delta \log \tilde{W}_{i t}, \Delta \log \tilde{W}_{i t-1}\right)=$ \\
$.0082(.0026)$ & $-.0324(.0043)$ \\
$\operatorname{Cov}\left(\Delta \log \tilde{h}_{i t}, \Delta \log \tilde{W}_{i t-2}\right)=$ & $\operatorname{Cov}\left(\Delta \log \tilde{W}_{i t}, \Delta \log \tilde{W}_{i t-2}\right)=$ \\
$.0021(.0026)$ & $-.0005(.0024)$
\end{tabular}

supply response to (the predictable component of) the remaining $99.45 \%$ of wage variation.

Table 4 reports the covariance of time $t$ measured hours and wage changes with time $t-1$ and $t-2$ wage changes. There is a negative covariance between current and lagged wage changes, indicating that if wages rose last year, they will fall this year. There is a positive covariance between current hours changes and lagged wage changes, indicating that if measured wages rose last year, measured hours will on average rise this year. If hours and wages were free of measurement error, table 4 would indicate that hours rise in response to a predictable decline in the wage. This would suggest a negative intertemporal elasticity of substitution. Given the presence of measurement error, no such inference should be made. The next subsection describes the measurement error corrections that will be made.

\section{B. Using the PSIDVS to Determine the Properties of Measurement Error in PSID Data}

In order to identify the properties of measurement error, I use the PSIDVS, described in Bound et al. (1994). A discussion of the survey design and results follows. The PSIDVS was designed to test the properties of measurement error in the PSID. Researchers from the University of Michigan surveyed employees at a single large Detroit-area manufacturing company in both 1983 and $1987 .{ }^{13}$ The employees who were interviewed in 1983 and were still employed by the firm in 1987 were reinterviewed, as were an additional sample of workers who were not interviewed in 1983. This creates a small panel of workers, as well as a somewhat larger cross section of workers. The design of this survey and the questions in it are similar to those in the PSID, although the PSIDVS asks fewer questions than the PSID.

The company records in the PSIDVS serve as a virtually error-free data set to compare with worker reports. I will therefore regard company measures of hours and wages as true hours and wages, $\log h_{i t}$ and $\log W_{i t}{ }^{14}$ The company

\footnotetext{
${ }^{13}$ Therefore, hours and earnings responses are for 1982 and 1986.

${ }^{14}$ Formally, true hours are $X_{i t} G+\log h_{i t}$ and true wages are $X_{i t} B+\log$ $W_{i t}$. So long as measurement error is uncorrelated with $X_{i t}$, it is not necessary to subtract $X_{i t} G$ from hours or $X_{i t} B$ from wages. There was a
} 
Table 5.-Covariances of Measurement Error: PSidVS

\begin{tabular}{lrr}
\hline \hline & Estimate (S.E.) & \multicolumn{1}{c}{$N$} \\
\hline $\operatorname{Cov}\left(\log W_{i 82}, u_{h i 82}\right)$ & $.0049(.0016)$ & 128 \\
$\operatorname{Cov}\left(\log W_{i 86}, u_{h i 86}\right)$ & $-.0009(.0006)$ & 292 \\
$\operatorname{Cov}\left(\log W_{i 82}, u_{h i 86}\right)$ & $-.0044(.0014)$ & 118 \\
$\operatorname{Cov}\left(\log W_{i 86}, u_{h i 82}\right)$ & $.0018(.0013)$ & 89 \\
$\operatorname{Cov}\left(\log h_{i 82}, u_{w i 82}\right)$ & $.0022(.0051)$ & 121 \\
$\operatorname{Cov}\left(\log h_{i 86}, u_{w i 86}\right)$ & $.0003(.0021)$ & 277 \\
$\operatorname{Cov}\left(\log h_{i 82}, u_{w i 86}\right)$ & $.0027(.0027)$ & 112 \\
$\operatorname{Cov}\left(\log h_{i 86}, u_{w i 82}\right)$ & $.0018(.0021)$ & 85 \\
$\operatorname{Cov}\left(u_{h i 82}, u_{w i 82}\right)$ & $-.0202(.0059)$ & 121 \\
$\operatorname{Cov}\left(u_{h i 86}, u_{w i 86}\right)$ & $-.0097(.0025)$ & 277 \\
$\operatorname{Cov}\left(u_{h i 82}, u_{w i 86}\right)$ & $-.0018(.0016)$ & 81 \\
$\operatorname{Cov}\left(u_{h i 86}, u_{w i 82}\right)$ & $.0001(.0018)$ & 83 \\
$\operatorname{Cov}\left(\log W_{i 82}, u_{w i 82}\right)$ & $-.0051(.0021)$ & 121 \\
$\operatorname{Cov}\left(\log W_{i 86}, u_{w i 86}\right)$ & $.0005(.0007)$ & 277 \\
$\operatorname{Cov}\left(\log W_{i 82}, u_{w i 86}\right)$ & $.0028(.0013)$ & 112 \\
$\operatorname{Cov}\left(\log W_{i 86}, u_{w i 82}\right)$ & $-.0032(.0020)$ & 85 \\
$\operatorname{Var}\left(u_{w i 82}\right)$ & $.0323(.0075)$ & 121 \\
$\operatorname{Var}\left(u_{w i 86}\right)$ & $.0172(.0026)$ & 277 \\
$\operatorname{Cov}\left(u_{w i 82}, u_{w i 86}\right)$ & $.0023(.0022)$ & 79 \\
\hline
\end{tabular}

has information on annual earnings and hours worked by all hourly employees. ${ }^{15}$ The company keeps records of earnings for tax purposes. The number of hours worked by hourly employees is measured by a punch clock. Therefore, the company has precise measures of both earnings and hours. Differences between company records and survey responses are attributed to measurement error on the part of the employee. Because the survey design of the PSIDVS is similar to that of the PSID, a worker's propensity to misreport earnings and hours should be similar in the two data sets.

Table 5 presents covariances between hours, wages, and measurement error in hours and wages for male hourly workers. Three important aspects of the data are worth noting. First, there is a negative covariance between measurement error in hours and wages. This is the division-bias problem. Second, there is a positive covariance between wages and measurement error in hours, as well as the positive covariance between hours and measurement error in wages. ${ }^{16}$ Inspection of equations (21) and (22) shows that mean-reverting measurement error tends to offset division bias. Lastly, there is evidence of serial correlation in measurement error. Failure to allow for serial correlation of measurement error will lead to an overstatement of the variance of transitory measurement error. This is important because the model is identified using transitory wage vari-

small negative correlation between the variance of measurement error and education. Because the PSIDVS sample has lower education than the PSID sample, this will lead to the variance of measurement error in the PSID being overestimated. However, the correlation was small and would not significantly affect the estimates.

${ }^{15}$ Hourly workers were paid overtime.

16 These covariances are a result of mean-reverting measurement error. Previous studies have found a negative covariance between true hours and measurement error in hours. Given that wages are imputed by dividing measured earnings by measured hours, it is unsurprising that there is a positive covariance between true hours and measurement error in wages and a positive covariance between true wages and measurement error in hours. ation. Therefore, if we overstate the amount of transitory wage variation attributable to measurement error, we will overstate the importance of division bias. Although the covariances between measurement error and true variables as well as the autocovariance of measurement error are statistically insignificant, they are fairly large in magnitude.

There are four major reasons why measurement error in the PSIDVS may not be comparable with measurement error in the PSID. The first reason is that I assume that the company records are perfect, and that the company records have been perfectly transcribed. Although the PSIDVS is of high quality, it is not perfect. ${ }^{17}$ This should cause the variance of measurement error to be overestimated, because measurement error on the part of the firm is being attributed to measurement error on the part of the individual.

The second reason why measurement error in the PSIDVS may not be comparable to measurement error in the PSID is that the PSIDVS samples a homogeneous group of workers. The PSIDVS respondents were all hourly work$\mathrm{ers}^{18}$ who worked for a single firm, and most worked full time. Table 2 shows that the standard deviations of reported wages and reported hours are much smaller in the PSIDVS sample than in the PSID sample. This may bias results, for the following reason. Recall that measurement error is potentially mean-reverting, that is, $\operatorname{Cov}\left(\log W_{i t}, u_{w i t}\right)<0$. Also note that in a sample with no variability in wages it must be the case that $\operatorname{Cov}\left(\log W_{i t}, u_{w i t}\right)=0$. Therefore, because there is less variability in wages in the PSIDVS than in the PSID, the importance of mean-reverting measurement error is likely smaller in the PSIDVS than in the PSID. Inspection of equations (21) and (22) shows that mean-reverting measurement error tends to offset the variances and covariances of measurement error. Given that the PSIDVS likely understates the importance of meanreverting measurement error, it likely overstates the importance of the division bias problem.

Third, most of the workers in the PSIDVS are older than those in the PSID, and all of them have remained with the same employer for several years. Therefore, it may be that the workers in the PSIDVS are familiar with their earnings and hours of work and are able to report the number of

\footnotetext{
${ }^{17}$ For example, one observation in the panel was deleted because the 1987 company report of an individual's earnings in 1982 was different from its 1983 report of the same individual's earnings in 1982. Although the discrepancy was small, it is evidence that there were transcription errors in 1983. Although I was able to delete this observation, there may be other observations that are erroneous company reports or other transcription errors.

${ }^{18}$ Both salaried and hourly workers were interviewed, but the company has records for hours worked only for hourly workers. Although the PSIDVS has no information about measurement error in hours for salaried workers, it does have information about measurement error in earnings (which is used to impute wages) for salaried workers. The variance of measurement error in earnings for salaried workers is 0.0232 , and that for hourly workers is 0.0221 , so the estimates for the two groups are not statistically different from each other. Likewise, the covariances of measurement error in earnings with reported hours and reported earnings are also not statistically different for the two groups.
} 
Table 6. -Estimates of the Intertemporal Elasticity of Substitution Under Different Measurement Error Assumptions: 1981 -1987 PSid; 1982 , 1986 PSIDVS

\begin{tabular}{|c|c|c|c|c|}
\hline Measurement error specification & (1) & (2) & (3) & (4) \\
\hline Any measurement error? & No & Yes & Yes & Yes \\
\hline Correlated with true variables? & No & No & Yes & Yes \\
\hline Includes MA(1) component? & No & No & No & Yes \\
\hline \multicolumn{5}{|c|}{ All Workers } \\
\hline \multicolumn{5}{|l|}{ First-Stage Estimates } \\
\hline$\gamma$ & $-.36(.02)$ & $-.26(.06)$ & $-.29(.05)$ & $-.31(.05)$ \\
\hline \multicolumn{5}{|l|}{ Second-Stage Estimates } \\
\hline $\operatorname{Cov}\left(\Delta \log h_{i t}, \Delta \log W_{i t-1}\right)$ & .0090 & -.0025 & -.0021 & .0005 \\
\hline $\operatorname{Cov}\left(\Delta \log W_{i t}, \Delta \log W_{i t-1}\right)$ & -.0366 & -.0156 & -.0203 & -.0221 \\
\hline Intertemporal elasticity of substitution, $\sigma$ & $-.25(.04)$ & $.16(.27)$ & $.10(.26)$ & $-.02(.23)$ \\
\hline \multicolumn{5}{|c|}{ Hourly Workers } \\
\hline$R^{2}$ & .144 & .069 & .093 & .101 \\
\hline \multicolumn{5}{|l|}{ Second-Stage Estimates } \\
\hline $\operatorname{Cov}\left(\Delta \log h_{i t}, \Delta \log W_{i t-1}\right)$ & .0082 & -.0033 & -.0029 & .0013 \\
\hline $\operatorname{Cov}\left(\Delta \log W_{i t}, \Delta \log W_{i t-1}\right)$ & -.0324 & -.0114 & -.0162 & -.0172 \\
\hline Intertemporal elasticity of substitution, $\sigma$ & $-.25(.08)$ & $.29(.40)$ & $.18(.33)$ & $-.08(.32)$ \\
\hline \multicolumn{5}{|l|}{$\begin{array}{l}\text { Standard errors in parentheses. } \\
\text { Column (1): } \sigma=\frac{\operatorname{Cov}\left(\Delta \log \tilde{h}_{i t}, \Delta \log \tilde{W}_{i t-1}\right)}{\operatorname{Cov}\left(\Delta \log \tilde{W}_{i t}, \Delta \log \bar{W}_{i t-1}\right)} . \\
\text { Column (2): } \sigma=\frac{\operatorname{Cov}\left(\Delta \log \tilde{h}_{i t}, \Delta \log \tilde{W}_{i t-1}\right)+\operatorname{Cov}\left(u_{h i t}, u_{w i t}\right)}{\operatorname{Cov}\left(\Delta \log \tilde{W}_{i t}, \Delta \log \bar{W}_{i t-1}\right)+\operatorname{Var}\left(u_{w i t}\right)}\end{array}$} \\
\hline
\end{tabular}

hours that they work more accurately than the population surveyed by the PSID. This indicates that the variance of measurement error might be underestimated in the PSIDVS.

Fourth, transitory wage shocks could be more or less important in this firm than for other firms. Potentially, both the variance of measurement error and the covariance of measurement error with true variables may be affected by the size of the transitory wage shocks. ${ }^{19}$ The extent of possible bias created by measurement problems in the PSIDVS is unclear. The next section reports results assuming that any possible bias is small.

\section{Results}

\section{A. Estimates Using Measurement Error Corrections}

Table 6 shows four estimates of the intertemporal elasticity of substitution, as well as first-stage statistics. The necessary covariances for estimation are in tables 4 and 5 . The sample selection criteria are described in appendix A. Appendices $\mathrm{C}$ and $\mathrm{D}$ describe computation of standard errors and the first-stage $F$ and $R^{2}$ statistics.

\footnotetext{
${ }^{19}$ Bound et al. (1994) show that both earnings and hours were significantly lower in 1982 than in 1986, possibly because of the 1982 recession. Table 5 shows that many of the variances and covariances of measurement error are larger in 1982 than in 1986.
}

The estimates in column (1) make no corrections for measurement error. The estimated intertemporal elasticity of substitution is negative. On assuming measurement error is white noise, as in column (2), the intertemporal elasticity of substitution is positive. ${ }^{20}$ The reason for the change in sign is that the estimates in column (2) allow for the divisionbias problem. As mentioned previously, failure to allow for measurement error results in downward-biased estimates of the intertemporal elasticity of substitution. However, the estimates in column (2) do not allow for the correlation between true variables and measurement error. Column (3) does so. It shows that allowing for mean-reverting measurement error reduces the estimated intertemporal elasticity of substitution. The estimates in column (3) assume that there is no MA(1) component to measurement error, however. Column (4) assumes that all covariation in hours and wage changes with twice lagged wage changes arises from measurement error. Making this assumption reduces the estimate of the intertemporal elasticity of substitution again. Although there are insufficient data to tell which assumption about the MA(1) component of measurement error is better,

\footnotetext{
${ }^{20}$ Note, however, that the standard errors are large. That is the result of the small sample size of the PSIDVS. It would useful to reestimate the model using new validation data if they become available.
} 
Table 7.-Estimates of the Intertemporal Elasticity of Substitution Under Different Instrument Sets: PSID, $1969-1996$

\begin{tabular}{|c|c|c|c|c|c|c|c|}
\hline & (1) & (2) & (3) & (4) & (5) & (6) & (7) \\
\hline Group: & All & All & Hourly & Hourly & Hourly & Hourly & Hourly \\
\hline Instrument: & $\Delta \log \tilde{W}_{i t-2}$ & $\log \tilde{W}_{i t-2}$ & $\begin{array}{c}\Delta \log \dot{W}_{i t-2} \\
\log \dot{W}_{i t-2}\end{array}$ & $\begin{array}{c}\Delta \log \\
\tilde{W}_{i t-2}\end{array}$ & $\begin{array}{l}\Delta \log \\
\dot{W}_{i t-2}\end{array}$ & $\log \tilde{W}_{i t-2}$ & $\log \dot{W}_{i t-2}$ \\
\hline \multicolumn{8}{|c|}{ First-Stage Estimates (Dependent Variable Is $\Delta \log \tilde{W}_{i t}$ ) } \\
\hline$\gamma$ & $-.023(.006)$ & $-.037(.003)$ & $\begin{array}{l}.014(.017) \\
-.036(.007)\end{array}$ & $-.20(.011)$ & $.010(.019)$ & $-.033(.005)$ & $-.023(.006)$ \\
\hline$F$ & 15.4 & 127.7 & 12.8 & 3.2 & .25 & 34.16 & 13.2 \\
\hline$R^{2}$ & 0.0005 & 0.0035 & 0.0022 & 0.0009 & 0.0000 & 0.0026 & 0.0010 \\
\hline$N$ & 31,620 & 36,331 & 11,706 & 9,874 & 9,874 & 13,193 & 13,193 \\
\hline \multicolumn{8}{|c|}{ Second-Stage Estimates (Dependent Variable Is $\Delta \log \tilde{h}_{i t}$ ) } \\
\hline $\operatorname{Cov}\left(\Delta \log \tilde{h}_{i t}\right.$, instrument $)$ & .00019 & .0010 & & .0003 & -.0004 & .0002 & -.0002 \\
\hline $\operatorname{Cov}\left(\Delta \log \tilde{W}_{i t}\right.$, instrument $)$ & -.00222 & -.0104 & & -.0013 & .0002 & -.0064 & -.0035 \\
\hline Intertemporal elasticity of substitution, $\sigma$ & $-.18(.18)$ & $-.10(.06)$ & $.18(.19)$ & $-.23(.48)$ & $-2.0(3.9)$ & $-.03(.15)$ & $.06(.25)$ \\
\hline
\end{tabular}

First stage regression: $\Delta \tilde{W}_{i t}=\delta+\gamma$ (instrument) $+\eta_{i t}$.

Standard errors in parentheses.

both columns (3) and (4) indicate an intertemporal elasticity of substitution that is close to 0 . Moreover, they are not statistically different from each other, regardless of whether or not the PSID sample is restricted to hourly workers. However, all estimates in columns (3) and (4) are statistically different from 0.7 and -0.5 on using all workers and are statistically different from 0.9 and -0.7 on using hourly workers, meaning that the estimates can reject a very large estimate of the intertemporal elasticity of substitution.

\section{B. Estimates Using Alternative Instruments for Wage Changes}

Table 7 presents estimates of the intertemporal elasticity of substitution using different instruments for the time $t$ wage change. The hours and wage change measures are again residuals from regressions on an age cubic, education, year dummies, and changes in health status. ${ }^{21}$ Of the seven sets of estimates, columns (1)-(3) use instrument sets similar to other author's. ${ }^{22}$ Column (1) uses an instrument set $(\Delta$ $\left.\log \tilde{W}_{i t-2}\right)$ similar to Abowd and Card's $(1987,1989)$. Column (2) uses an instrument set $\left(\log \tilde{W}_{i t-2}\right)$ used by Holtz-Eakin et al. (1988). Column (3) uses an instrument set similar to that of Altonji (1986), who uses both the level and first difference of the first lag of the reported current hourly wage of hourly workers, denoted $\log \dot{W}_{i t-1}$ and $\Delta \log$ $\dot{W}_{i t-1}$, to instrument for $\Delta \log \tilde{W}_{i t-2}$. Because the two measures are constructed differently, the measurement errors in $\log \dot{W}_{i t-1}$ and in $\Delta \log \dot{W}_{i t-1}$ should be uncorrelated with the measurement error in $\log \tilde{W}_{i t}{ }^{23}$ This overcomes the

\footnotetext{
${ }^{21}$ I also tried a more standard approach: include the age cubic, education, year dummies, and changes in health status as right-side regressors in the second stage. That did not lead to substantially different estimates.

${ }^{22}$ Data from 1969 to 1996 were used in the analysis, although the same coding decisions (outlined in appendix A) were used as in the previous subsection.

${ }^{23}$ Altonji (1986) notes that the current hourly wage measure $\dot{W}_{i t}$ refers to the wage at the time of the interview, whereas the earnings-dividedby-hours measure $\tilde{W}_{i t}$ refers to hours and earnings over the previous calendar year. In order to make the two wage measures refer to the same
}

division-bias problem. Unfortunately, it is likely that most of the transitory wage variation comes from overtime and bonuses. Moreover, $\dot{W}_{i t}$ refers to a given point in time, whereas the relevant wage measure is the wage over the calendar year. Therefore, most of the year-to-year variation in the hourly wage is likely missing when using $\dot{W}_{i t}$. This will reduce the predictive power of the first-stage $R^{2}$ and will also make measurement error in this wage measure negatively correlated with the true wage. If the measurement error in $\dot{W}_{i t}$ is negatively correlated with the true wage, the measure becomes an invalid instrument.

Columns (1)-(3) show that the estimates of the intertemporal elasticity of substitution are higher when using $\log \dot{W}_{i t}$ than when using $\log \tilde{W}_{i t}$ as an instrument. One possible reason for this discrepancy is that serially correlated measurement error in $\log \tilde{W}_{i t}$ is biasing the estimated intertemporal elasticity of substitution downward. In section IID I showed that serially correlated measurement error most likely biases the intertemporal elasticity of substitution downward when using either $\log \tilde{W}_{i t}$ or $\Delta \log \tilde{W}_{i t}$ as an instrument. In columns (4) and (5) the sample is restricted to hourly workers who have data on $\Delta \log \dot{W}_{i t-2}$ and $\Delta \log$ $\tilde{W}_{i t-2}$. In columns (6) and (7) the sample is restricted to hourly workers who have data on both $\log \dot{W}_{i t-2}$ and $\log$ $\tilde{W}_{i t-2}$. Because the same people are being used to estimate the intertemporal elasticity of substitution, we should think that both $\log \dot{W}_{i t-2}$ and $\log \tilde{W}_{i t-2}$ should yield the same results and both $\Delta \log \dot{W}_{i t-2}$ and $\Delta \log \tilde{W}_{i t-2}$ should yield the same results in the absence of serially correlated measurement error. If serially correlated measurement error is affecting estimates when using the $\log \tilde{W}_{i t}$ measure of wages, then we should see higher estimates of $\operatorname{Cov}(\Delta \log$ $\tilde{h}_{i t}$, instrument $)$ and lower estimates of $\operatorname{Cov}\left(\Delta \log \tilde{W}_{i t}\right.$, instrument) when using $\log \tilde{W}_{i t-2}$ instead of $\log \dot{W}_{i t-2}$ as the instrument. It appears that there is evidence for this

time period, I use the hours and earnings measures reported at time $t+1$ to generate $\tilde{W}_{i t}$. 
claim, although the differences are statistically insignificant. Therefore, there is some evidence that serially correlated measurement error leads to downward-biased estimates of the intertemporal elasticity of substitution when using twice lagged wages. ${ }^{24}$ However, the most important thing to note is that all estimates are close to 0 . These results, combined with the results in the previous subsection, show that the person-specific year-to-year variation in hours is uncorrelated with that in wages.

\section{Conclusions}

In this paper I estimate the labor supply response to predictable wage changes. Using data from the PSID and the PSIDVS, I find a large transitory component to wages, even after correcting for measurement error. Because, by definition, the transitory component of wages vanishes over time, workers should anticipate that transitory wage shocks should vanish. This means that workers can predict some wage changes, and thus the labor supply response to these predicable wage changes identifies the intertemporal elasticity of substitution.

Using data from the PSIDVS, I find that that measurement error in hours and wages is correlated with true hours and wages. I also find that measurement error is serially correlated. This violates the assumptions of many previous PSID studies of intertemporal labor supply and will most likely lead to downward-biased estimates of the intertemporal elasticity of substitution.

However, properly controlling for measurement error does not overturn the qualitative findings of the previous PSID studies. Depending on the assumed autocorrelation structure for measurement error, point estimates are -0.03 to 0.10 with a standard error of 0.25 . A conservative range for the intertemporal elasticity of substitution is -0.5 to 0.6 . Although the range is wide, an estimate 0.6 is still well below the elasticities used in the real-business-cycle literature.

\section{REFERENCES}

Abowd, J., and D. Card, "Intertemporal Labor Supply and Long Term Contracts," American Economic Review 77 (March 1987), 50-68.

Abowd, J., and D. Card, "On the Covariance Structure of Earnings and Hours Changes," Econometrica 57:2 (1989), 411-445.

Altonji, J., "Intertemporal Substitution in Labor Supply: Evidence from Microdata," Journal of Political Economy 94 (1986), S176-S215.

Altonji, J., and L. Segal, "Small Sample Bias in GMM Estimation of Covariance Structures," Journal of Business and Economic Statistics 14:3 (1994), 353-366.

Bound, J., C. Brown, G. Duncan, and W. Rogers, "Evidence on the Validity of Cross-Sectional and Longitudinal Labor Market Data," Journal of Labor Economics 12 (1994), 345-368.

Bound, J., C. Brown, and N. Mathiowetz, "Measurement Error in Survey Data," in J. Heckman and E. Leamer (Eds.), Handbook of Econometrics, vol. 5 (North-Holland, 2001).

${ }^{24}$ Ziliak and Kniesner (1999) also find evidence that the $\tilde{W}_{i t}$ measure leads to downward-biased estimates.
Bound, J., D. Jaeger, and R. Baker, "Problems with Instrumental Variables Estimation When the Correlation between the Instruments and the Endogenous Explanatory Variable Is Weak," Journal of the American Statistical Association 90:430 (1992), 443-450.

Bound, J., and A. Krueger, "The Extent of Measurement Error in Longitudinal Earnings Data: Do Two Wrongs Make a Right?," Journal of Labor Economics 9 (1991), 1-24.

Camerer, C., L. Babcock, G. Lowenstein, and R. Thaler, "One Day at a Time: An Empirical Analysis of Cab Drivers," Quarterly Journal of Economics 112:2 (1997), 407-441.

Carrington, W., "The Alaskan Labor Market during the Pipeline Era," Journal of Political Economy 104:1 (1996), 186-218.

Ham, J., and K. Reilly, "Testing Intertemporal Substitution, Implicit Contracts, and Hours Restrictions Models of the Labor Market Using Micro Data," American Economic Review 92:4 (2002), 905927.

Heckman, J., "What Has Been Learned about Labor Supply in the Past Twenty Years?" American Economic Review 83:2 (1993), S116S121.

Holtz-Eakin, D., W. Newey, and H. Rosen, "Estimating Vector Autoregressions with Panel Data," Econometrica 56:6 (1988), 1371-1395.

Lee, C., "Finite Sample Bias in IV Estimation of Intertemporal Labor Supply Models: Is the Intertemporal Substitution Elasticity Really Small?" this REVIEW, 83:4 (2001), 638-646.

MaCurdy, T., "An Empirical Model of Labor Supply in a LifeCycle Setting," Journal of Political Economy 89:6 (1981), 1059-1085.

MaCurdy, T., "Interpreting Empirical Models of Labor Supply in an Intertemporal Framework with Uncertainty," in J. Heckman and B. Singer (Eds.), Longitudinal Analysis of Labor Market Data, (Cambridge University Press, 1985).

Mulligan, C., "The Intertemporal Substitution of Work-What Does the Evidence Say?" University of Chicago manuscript (1995).

Mulligan, C., "Substitution over Time: Another Look at Life Cycle Labor Supply," (pp. 75-134), in NBER Macro Annual 1998 (1999).

Nelson, C., and R. Startz, "Some Further Results on the Exact Small Sample Properties of the Instrumental Variables Estimator," Econometrica 58:4 (1990), 967-976.

Oettinger, G., "An Empirical Analysis of the Daily Labor Supply of Stadium Vendors," Journal of Political Economy 107 (April 1999), 360-392

Rosen, S., "Implicit Contracts: A Survey," Journal of Economic Literature 23 (1985), 1144-1175.

Staiger, D., and James Stock, "Instrumental Variables Regression with Weak Instruments," Econometrica 65 (1997), 557-586.

Ziliak, J. and Kniesner, "Estimating Life Cycle Labor Supply Tax Effects," Journal of Political Economy 107:2 (1999), 326-359.

\section{APPENDIX A}

\section{Sample Selection Criteria}

Below are the sample selection criteria used for analysis. Table A1 describes the sample selection criteria that were used. The left-side column refers to the selection criteria; the next four columns refer to observations deleted from the PSIDVS, where R refers to respondent observations and V refers to the validation (that is, firm) observation of the individual. The right-hand column refers to observations from the PSID. The initial subsample consisted of all males in the relevant years with hours greater than 0 .

A "- " implies that the sample selection criterion was not used to delete observations. The only selection criteria used for the validation reports are that they must not be missing and that the firm reports must be internally consistent (that is, that a firm's 1987 report of a worker's 1982earnings must be the same as the 1983 report of the same worker's earnings). I use no other criteria for the validation reports in the PSIDVS because I have no information on the true measures of hours and wages in the PSID. For 1983 I delete respondent reports of multiple jobholders because the hours question refers to hours on all jobs, whereas the validation report refers only to hours worked on the main job. For 1987 
Table A1.-Sample Selection

\begin{tabular}{|c|c|c|c|c|c|}
\hline Criterion for Deletion & $1983(\mathrm{R})$ & $1983(\mathrm{~V})$ & $1987(\mathrm{R})$ & $1987(\mathrm{~V})$ & PSID \\
\hline Initial observations & 339 & 173 & 449 & 296 & 19,160 \\
\hline Age $<25$ or age $>65$ & 4 & 0 & 10 & 3 & 2,130 \\
\hline Hours were assigned & 50 & - & 9 & - & 476 \\
\hline Multiple jobholders & 23 & - & - & - & - \\
\hline Firm is not main job & - & - & 2 & - & - \\
\hline \multicolumn{6}{|c|}{ Wages } \\
\hline Earnings missing & 7 & 0 & 0 & 0 & 0 \\
\hline Wages $<\$ 3$ or $>\$ 100$ (1987 dollars $)$ & 0 & - & 0 & - & 569 \\
\hline Earnings accuracy & - & - & 28 & - & 258 \\
\hline 1987 validation data different from 1983 validation data & - & 1 & - & - & - \\
\hline Missing education or health & - & - & - & - & 14 \\
\hline
\end{tabular}

the hours question refers to the main job. Two respondents reported the firm was not their main job.

I also deleted observations where there were earnings and hours assignments (that is, the reports were inaccurate). Unfortunately, earnings in 1983 were missing the assignment variable.

\section{APPENDIX B}

\section{Derivation of Estimating Equations}

This appendix gives the algebra behind equations (17) and (18). The numerator for the equation for $\sigma$, equation (17), is ${ }^{25}$

$$
\begin{aligned}
\operatorname{Cov}( & \left.\Delta \log h_{i t}, \Delta \log W_{i t-1}\right) \\
= & \operatorname{Cov}\left(\Delta \log \tilde{h}_{i t}-\Delta u_{h i t}, \Delta \log \tilde{W}_{i t-1}-\Delta u_{w i t-1}\right) \\
= & \left.\operatorname{Cov}\left(\Delta \log \tilde{h}_{i t}, \Delta \log \tilde{W}_{i t-1}\right)\right)-\operatorname{Cov}\left(\Delta u_{h i t}, \Delta W_{i t-1}+\Delta u_{w i t-1}\right) \\
& -\operatorname{Cov}\left(\Delta \log h_{i t}+\Delta u_{h i t}, \Delta u_{w i t-1}\right)+\operatorname{Cov}\left(\Delta u_{h i t}, \Delta u_{w i t-1}\right) \\
= & \operatorname{Cov}\left(\Delta \log \tilde{h}_{i t}, \Delta \log \tilde{W}_{i t-1}\right)-\operatorname{Cov}\left(\Delta u_{h i t}, \Delta \log W_{i t-1}\right) \\
& -\operatorname{Cov}\left(\Delta \log h_{i t}, \Delta u_{w i t-1}\right)-\operatorname{Cov}\left(\Delta u_{h i t}, \Delta u_{w i t-1}\right) \\
= & \operatorname{Cov}\left(\Delta \log \tilde{h}_{i t}, \Delta \log \tilde{W}_{i t-1}\right) \\
& -\operatorname{Cov}\left(v_{h i t}-\left(1-\theta_{h}\right) v_{h i t-1}-\theta_{h} v_{h i t-2}, \log W_{i t-1}-\log W_{i t-2}\right) \\
& -\operatorname{Cov}\left(\log h_{i t}-\log h_{i t-1}, v_{w i t-1}-\left(1-\theta_{w}\right) v_{w i t-2}-\theta_{w} v_{w i t-3}\right) \\
& -\operatorname{Cov}\left(v_{h i t}-\left(1-\theta_{h}\right) v_{h i t-1}-\theta_{h} v_{h i t-2}, v_{w i t-1}\right. \\
& \left.-\left(1-\theta_{w}\right) v_{w i t-2}-\theta_{w} v_{w i t-3}\right) \\
= & \operatorname{Cov}\left(\Delta \log \tilde{h}_{i t}, \Delta \log \tilde{W}_{i t-1}\right)+\left(1-2 \theta_{h} h+\theta_{h} \theta_{w}\right) \operatorname{Cov}\left(v_{h i t}, v_{w i t}\right) \\
& +\operatorname{Cov}\left(v_{w i t}, \log h_{i t}\right)+\left(1-2 \theta_{h}\right) \operatorname{Cov}\left(v_{h i t}, \log W_{i t}\right),
\end{aligned}
$$

and the denominator of $\sigma$ is

$$
\begin{aligned}
\operatorname{Cov}( & \left.\Delta \log W_{i t}, \Delta \log W_{i t-1}\right) \\
= & \operatorname{Cov}\left(\Delta \log \tilde{W}_{i t}-\Delta u_{w i t}, \Delta \log \tilde{W}_{i t-1}-\Delta u_{w i t-1}\right) \\
= & \operatorname{Cov}\left(\Delta \log \tilde{W}_{i t}, \Delta \log \tilde{W}_{i t-1}\right)-\operatorname{Cov}\left(\Delta \log W_{i t}+\Delta u_{w i t}, \Delta u_{w i t-1}\right) \\
& -\operatorname{Cov}\left(\Delta u_{w i t}, \Delta \log W_{i t-1}+\Delta u_{w i t-1}\right)+\operatorname{Cov}\left(\Delta u_{w i t}, \Delta u_{w i t-1}\right)
\end{aligned}
$$

\footnotetext{
${ }^{25}$ Recall that because $\log h_{i t}$ is a variable with zero mean and $\log W_{i t-1}$ is a variable, $\operatorname{Cov}\left(\log h_{i t}, \log W_{i t-1}\right)=E\left(\log h_{i t} \log W_{i t-1}\right)$.
}

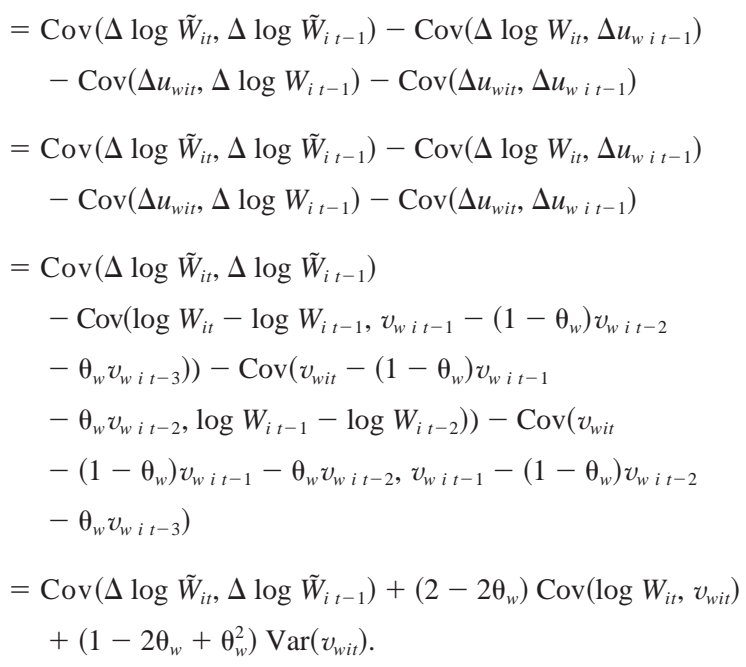

\section{APPENDIX C}

\section{Obtaining Standard Errors}

This appendix describes the procedure to obtain standard errors for both the first-stage wage regression and the second-stage estimate of the intertemporal elasticity of substitution. Estimation of the two is similar, so I focus on estimates of the intertemporal elasticity of substitution, for concreteness.

There are several econometric problems in estimating the standard error. First, estimates of $\operatorname{Cov}\left(\Delta \log \tilde{h}_{i t}, \Delta \log \tilde{W}_{i t-1}\right)$ and $\operatorname{Cov}\left(\Delta \log \tilde{W}_{i t}, \Delta\right.$ $\log \tilde{W}_{i t-1}$ ) come from the PSID, whereas the other objects come from the PSIDVS. Second, the estimate of $\operatorname{Cov}\left(\Delta \log \tilde{h}_{i t}, \Delta \log \tilde{W}_{i t-1}\right)$, for example, uses several years of data on the same individual, meaning that not all observations are independent of one another. Third, the same individuals are not observed in all years, making the data unbalanced. The procedure below addresses all three problems.

Consider a highly simplified version of the problem where

$$
\hat{\sigma}=\frac{\frac{1}{N_{A}+N_{B}}\left(\sum_{i=1}^{N_{A}} A_{i}+\sum_{i=1}^{N_{B}} B_{i}\right)}{\frac{1}{N_{U}+N_{V}}\left(\sum_{i=1}^{N_{U}} U_{i}+\sum_{i=1}^{N_{V}} V_{i}\right)}=\frac{\bar{S}}{\bar{T}},
$$

where $A_{i}$ and $B_{i}$ are individual contributions to a covariance (for example, $A_{i}=\Delta \log \tilde{h}_{i 85} \Delta \log \tilde{W}_{i 84}-E\left[\Delta \log \tilde{h}_{i t} \Delta \log \tilde{W}_{i t}\right]$ and $B_{i}=\Delta \log$ 


$$
\hat{W}=\left|\begin{array}{lll}
\left(\frac{1}{N_{A}+N_{B}}\right)^{2} \sum_{i=1}^{N_{A}}\left(A_{i}-\bar{A}\right)^{2} & \left(\frac{1}{N_{A}+N_{B}}\right)^{2} \sum_{i=1}^{N_{A} \cap N_{B}}\left(A_{i}-\bar{A}\right)\left(B_{i}-\bar{B}\right) & \ldots \\
\left(\frac{1}{N_{A}+N_{B}}\right)^{2} \sum_{i=1}^{N_{A} \cap N_{B}}\left(A_{i}-\bar{A}\right)\left(B_{i}-\bar{B}\right) & \left(\frac{1}{N_{A}+N_{B}}\right)^{2} \sum_{i=1}^{N_{B}}\left(B_{i}-\bar{B}\right)^{2} & \ldots \\
\left(\frac{1}{N_{A}+N_{B}}\right)\left(\frac{1}{N_{U}+N_{V}}\right) \sum_{i=1}^{N_{A} \cap N_{B}}\left(A_{i}-\bar{A}\right)\left(U_{i}-\bar{U}\right) & \left(\frac{1}{N_{A}+N_{B}}\right)\left(\frac{1}{N_{U}+N_{V}}\right) \sum_{i=1}^{N_{B} \cap N_{U}}\left(B_{i}-\bar{B}\right)\left(U_{i}-\bar{U}\right) & \ldots \\
\left(\frac{1}{N_{A}+N_{B}}\right)\left(\frac{1}{N_{U}+N_{V}}\right) \sum_{i=1}^{N_{A} \cap N_{V}}\left(A_{i}-\bar{A}\right)\left(V_{i}-\bar{V}\right) & \left(\frac{1}{N_{A}+N_{B}}\right)\left(\frac{1}{N_{U}+N_{V}}\right) \sum_{i=1}^{N_{B} \cap N_{V}}\left(B_{i}-\bar{B}\right)\left(V_{i}-\bar{V}\right) & \ldots
\end{array}\right| .
$$

$\tilde{h}_{i 86} \Delta \log \tilde{W}_{i 85}-E\left[\Delta \log \tilde{h}_{i t} \Delta \log \tilde{W}_{i t}\right]$, and $N_{A}, N_{B}, N_{C}$, and $N_{D}$ are the numbers of observations in covariances $A, B, C$, and $D$. Assuming that the wage and hours generating process is stationary, ${ }^{26} \mathrm{I}$ also enforce the restriction that

$$
\left.\bar{A}=\bar{B}=\frac{1}{N_{A}+N_{B}}\left(\sum^{N_{A}} A_{i}+\sum^{N_{B}} B_{i}\right)\right)
$$

and

$$
\bar{C}=\bar{D}=\frac{1}{N_{C}+N_{D}}\left(\sum C_{i}+\sum^{N_{C}} D_{i}\right)
$$

as they are both means of the same object. Embodied in this problem are all three previously mentioned problems.

Denote $N_{B}=N_{B}\left(N_{A}\right), N_{C}=N_{C}\left(N_{A}\right), N_{D}=N_{D}\left(N_{A}\right)$ to indicate that $N_{B}, \quad N_{C}, \quad N_{D}$ are to be viewed as functions of $N_{A}$. Assume $\lim _{N_{A} \rightarrow \infty} N_{B}\left(N_{A}\right)=k_{B}, \lim _{N_{A} \rightarrow \infty} N_{C}\left(N_{A}\right)=k_{C}, \lim _{N_{A} \rightarrow \infty} N_{D}\left(N_{A}\right)=k_{D}$, where $k_{B}, k_{C}, k_{D}$ are constants. In other words, the numbers of observations in the moment conditions $(A, B, C, D)$ are all converging to infinity at the same rate. Moreover, assume that

$$
\operatorname{plim}_{N_{A} \rightarrow \infty} \frac{1}{N_{A}+N_{B}}\left(\sum_{i=1}^{N_{A}} A_{i}+\sum_{i=1}^{N_{B}} B_{i}\right)=E(A)
$$

and

$$
\operatorname{plim}_{N_{A} \rightarrow \infty} \frac{1}{N_{U}+N_{V}}\left(\sum_{i=1}^{N_{U}} U_{i}+\sum_{i=1}^{N_{V}} V_{i}\right)=E(U) .
$$

Performing a Taylor's series expansion of $\hat{\sigma}$ in equation (C-1) around $\sigma$ and squaring results in the delta method. Written in matrix format, the delta method is

$$
(\sigma-\hat{\sigma}) \sim_{a} N\left(0,\left(\frac{\partial \sigma}{\partial m}\right){ }^{\prime} W\left(\frac{\partial \sigma}{\partial m}\right)\right),
$$

where $m$ is a covariance, such as $E(A)$, and $W$ is the fourth moment matrix of the covariances needed to estimate equation (C-1). In practice, $(\partial \sigma / \partial m)$ and $W$ are replaced by their sample analogs:

$$
\frac{\partial \hat{\sigma}}{\partial \bar{m}}=\left(\begin{array}{c}
1 / \bar{T} \\
1 / \bar{T} \\
-\bar{S} / \bar{T}^{2} \\
-\bar{S} / \bar{T}^{2}
\end{array}\right),
$$

${ }^{26}$ The stationarity assumption is not necessary for estimation of $\sigma$, but it simplifies the computation of the standard errors.
$\hat{W}$ is a symmetric matrix. $N_{A} \cap N_{B}$ refers to the number of persons that contributed to both the $A_{i}$ covariance and the $B_{i}$ covariance. Note that if $A_{i}$ and $U_{i}$ are from different data sets, $N_{A} \cap N_{V}=0$. Therefore, if $A$ and $B$ were from one data set and $C$ and $D$ were from another data set, $\hat{W}$ would be a block-diagonal matrix. In practice, estimation of $\hat{\sigma}$ and its distribution is more tedious but no more complicated than what is described in this section. For example, in the absence of measurement error, the equation for $\hat{\sigma}$ will have five objects in the numerator and five in the denominator (one for each year of PSID data), meaning that $(\partial \hat{\sigma} / \partial \bar{m})$ is a $10 \times 1$ vector and $\hat{W}$ is a $10 \times 10$ matrix.

\section{APPENDIX D}

\section{Derivation of the First-Stage Regression}

This appendix shows the procedure to control for measurement error in the first-stage regression (10) as well as the procedure to obtain the relevant first stage $F$-statistic and $R^{2}$ statistic. The results from Altonji and Segal (1994), Nelson and Startz (1990), and Staiger and Stock (1997) imply that my estimator is biased in small samples, and that the $F$-statistic and $R^{2}$ statistic are useful diagnostics for understanding this bias. The procedure to control for measurement error is fundamentally similar to the procedure used to control for measurement error when estimating $\sigma$ directly. Consider the case where $\theta_{h}=\theta_{w}=0$, but measurement error is correlated with true variables, as in column (3) of table 6 . The regression coefficient in the first stage is

$$
\begin{aligned}
\gamma & =\frac{\operatorname{Cov}\left(\Delta \log W_{i t}, \Delta \log W_{i t-1}\right)}{\operatorname{Var}\left(\Delta \log W_{i t-1}\right)} \\
& =\frac{\operatorname{Cov}\left(\Delta \log \tilde{W}_{i t}-v_{w i t}, \Delta \tilde{W}_{i t-1}-v_{w i t-1}\right)}{\operatorname{Var}\left(\Delta \log \tilde{W}_{i t-1}-v_{w i t-1}\right)} \\
& =\frac{\operatorname{Cov}\left(\Delta \log \tilde{W}_{i t}, \Delta \log \tilde{W}_{i t-1}\right)+2 \operatorname{Cov}\left(\log W_{i t}, v_{w i t}\right)+\operatorname{Var}\left(v_{w i t}\right)}{\operatorname{Var}\left(\Delta \log \tilde{W}_{i t-1}\right)-4 \operatorname{Cov}\left(\log W_{i t}, v_{w i t}\right)-2 \operatorname{Var}\left(v_{w i t}\right)} .
\end{aligned}
$$

Standard errors for $\gamma$ are computed using the method described in appendix C. The $t$-statistic is $\gamma$ divided by its standard error. The $F$-statistic is the square of the $t$-statistic. The $R^{2}$ is the explained sum of squares divided by the total sum of squares. An appendix available from the author describes the potential small-sample bias in this problem. If the series $\Delta \log W_{i t}$ is stationary, then the $R^{2}$ is

$$
R^{2}=\frac{\sum_{i=1}^{N}\left(\hat{\gamma} \Delta \log W_{i t}\right)^{2}}{\sum_{i=1}^{N}\left(\Delta \log W_{i t+1}\right)^{2}} \approx \hat{\gamma}^{2} .
$$

